\title{
The Pedagogical Technique for Teachers to Ensure Information Security of the Learning Process in the Context of the COVID-19 Pandemic
}

\author{
Utkina O.N. ${ }^{1, *}$ Yugova N.L. ${ }^{2}$ \\ ${ }^{1}$ Saint-Petersburg University of Management Technologies and Economics, Saint Petersburg, Russia \\ ${ }^{2}$ Glazov State Pedagogical Institute named V.G. Korolenko, Glazov, Russia \\ *Corresponding author. Email: may08_08@mail.ru
}

\begin{abstract}
The coronavirus (COVID-19) pandemic has affected all areas of public life, including the education system. The introduction of restrictive measures (social self-isolation) to contain COVID-19 has led to changes in the work of educational organizations. All subjects of education: teachers, students, and their parents have to adapt technically and psychologically to new learning conditions, mastering various forms of distance interaction on the Internet. Special programs and applications allow you to exchange information and files. Each of them has its own advantages and disadvantages, their use is fraught with certain threats, as is the case with any other services on the Internet. The article actualizes the problem of the effectiveness of the teacher's pedagogical technique in the context of the massive use of distance educational technologies. This article analyzes the risk and threats factors of the modern information society, which rise the need to improve the qualifications of all subjects of the educational process to ensure the information security of the educational environment. The idea of the need for the design, development, and implementation of advanced training courses for teachers of educational organizations, dedicated to information security and the use of distance learning technologies in the system of additional education, is substantiated. Information and communication competence is considered as a category component of a teacher's pedagogical technique. The results of surveys of teachers, children, and their parents are presented, based on which the relevance and content of individual modules of advanced training courses for teachers as a condition for increasing the effectiveness of their pedagogical technique are defined and characterized.
\end{abstract}

Key words: information security, information and psychological security, pedagogical technique, remote

educational technologies, coronavirus pandemic

\section{INTRODUCTION}

A modern educational organization is a multi-component system, the elements of which are the subjects of the educational process: students, their parents, teachers, administration. Nowadays, in the context of measures to prevent the spread of coronavirus infection, distance learning technologies (DLT) are in demand like never before. It is no secret that DLT provide fundamentally new opportunities for organizing educational and extracurricular activities, students' creativity, but at the same time, they pose a threat to their individual. Whereas

one of the main requirements for the educational environment is the information security of the individual. Information security is a state in which there is no risk associated with the infliction of harm to one's health, physical, mental, spiritual, and moral development by information, including information circulated on the Internet, (Federal Law on the Protection of Children from Information Causing Harm their health and development dated December 29, 2010, No. 436-FZ).

By negative information and psychological impact we mean the impact on the mental health of a teenager, carried out using special means and methods that prevent the harmonious development of the individual and lead to negative consequences. These include distorted patterns of perception of the living and integral world, the propaganda of aggressive forms of behavior towards peers, the narrowing of the scope of joint activities of parents and children in the family, school, the immediate environment of peers, and manifestations of deviant behavior. Special attention should be paid to the behavior of children on the Internet.

It should be noted that this is an interdisciplinary problem in nature. Therefore, let's consider the concepts of "information and psychological security" and "information security" synonymous and use the concept of "information security" onwards. Also, within the framework of this article, the concepts "teacher" and "pedagogue" will be considered interchangeable.

For modern children, the Internet is no longer just a technology, but a natural habitat. It gives access to arrays of various kinds of information of unlimited volumes. At the same time, there are usually no educational strategies, 
psychological and pedagogical tools for identifying and maintaining an individual's resources in a situation of environmental interaction on the Internet [1].

When organizing an information-safe educational environment that prevents harm from dangerous informational influences on the student, a modern teacher needs to have knowledge in psychology, a certain pedagogical technique, including the ability to work with DLT.

In the conditions of forced mass distance learning, becomes relevant the development of teacher's pedagogical technique, the development of advanced training courses on information security, the use of DLT, the organization of students' work in the context of the use of DLT, etc. It is necessary to determine the content of individual modules, taking into account the age characteristics and educational needs of students.

The use of information technologies by teachers in professional and pedagogical activities is due to their information and communication (IC) competence.

The formation of an IC competence by teachers involves not only the development of knowledge and skills in information processing and the use of information and communication technologies, DLT. The modern education system is characterized by an increase in the importance of electronic and distance learning formats. Then the teacher's communicative skills, implemented in the conditions of education informatization, come out on top.

We consider the IC competence of a teacher as a category component of pedagogical technique. In general, we understand the pedagogical technique as a form of a teacher's behavior organization.

\section{RESEARCH METHODS}

V.M. Myndykanu, V.A. Slastenin, N.N. Tarasevich, N.E. Shchurkova and others, in general terms, understand pedagogical technique as "a set of skills and abilities that are necessary for the effective application of the system of methods of pedagogical influence on individual students and the collective as a whole" [2, p. 335].

Conventionally, two groups of abilities are distinguished: 1 ) the ability to manage oneself (posture, facial expressions, gestures, pantomimic), manage one's emotional state (relieve excess psychological stress, induce a state of creative well-being), speech technique (breathing, voice formation, diction, speech rate); 2) the ability to influence the individual and the collective (the technique of organizing contacts, managing pedagogical communication; infusion technique, etc.).

If we consider pedagogical technique in the works of foreign authors, they provide useful advices, and also propose specific methods for managing the educational process in the classroom, similar to the techniques given in domestic textbooks on pedagogical skills.

The traditional solution to the problem of the development of pedagogical technique is to attract an intuitive approach, which often entails pedagogical errors, an unjustified increase in the training time and energy costs of all participants in the educational process.

Another approach based on the use of a pedagogical system, built using instrumental measurements is given [3]. The system is based on the idea of identifying positive and negative techniques of the teacher's pedagogical technique according to the collective opinion of experts [4]. A positive technique is a technique that reinforces the teacher's words or at least does not oppose them, as opposed to a negative technique.

In modern conditions of combating the spread of coronavirus infection and the widespread use of distance learning technologies, the question of developing a system of measures to improve the information and psychological safety of students is urgent. When studying information and psychological security issues, we relied on the works of I.A. Baeva, Yu.I. Bogatyryova, G.V. Grachyov, V.P. Polyakov, A.N. Privalov, in which the complexity and ambiguity of learning problems in a new educational environment are proved $[5,6,7]$. The N.I. Sattarova's dissertation is devoted to the pedagogical conditions for ensuring the information security of students using the Internet in education [8]. The social and psychological perspective of teenagers and teachers on the Internet environment $[9,10,11]$. The information and psychological security of a person is considered by us as a set of internal personal resources (emotional, cognitive, value-based), mechanisms of psychological defense against destructive information [1]. Scientific and methodological work was carried out in the form of various measurements in the system of quality improvement of professional training of educators through consultations, training, coaching, seminars, individual and group conversations. The following were taken into account: the quality of the organization of the educational environment (educational and methodological, employee, information, technical support); procedural component (forms, methods, technologies used by teachers, their performance level); the resulting component (achievement of the set goals, improvement of professional competence).

\section{RESEARCH RESULTS}

In the context of the use of DLT, teachers are tasked with giving knowledge and developing students' skills for the safe receipt of information from the global network.

Despite a fairly large number of works devoted to these issues, the formulated recommendations for teachers are often only declarative in nature [12]. Let's consider some of them.

1. Middle-aged and older students can spend up to two hours a day in front of the monitor, taking 10-15 minute breaks every half hour.

The first part of this recommendation is more related to those employees of the educational organization who make the schedule. Note that if a general education organization tries to follow this rule, then only parents can be responsible for the duration of a child's stay at the computer at home.

2. It is better to work on a computer in the first half of the day. 
And what if the child learns remotely from home. As the training practice has shown (from March to June 2020), the process of homeschooling becomes almost continuous throughout the day: it starts early in the morning and ends in the late evening. All this time the student is forced to interact with various information gadgets: computer, phone, tablet. At the same time, pedagogical didactics cannot offer the modern teacher, and even parents, optimal methodological recommendations for organizing a safe (in every sense) learning process.

3. When working on a computer, monitor your posture, furniture should match your height.

Students in the period of study in secondary school already have different physical characteristics. So, in the same class there can be students of different heights. It is almost impossible to choose furniture suitable for everyone and to correctly arrange the lighting sources.

When homeschooling, the situation is no better. Not all parents have the financial means to equip an ergonomically correct workplace for their child's education. If distancelearning takes place at home using a laptop, the student can be in a half-sitting and reclining position. At school, the teacher is obliged to monitor this, but what about home? And what about when there are several children in a family and they have classes at the same time?

4. To ensure the student's Internet safety, teachers are required to convince them to report if something or someone on the network harasses or threatens them.

It is completely incomprehensible how the teacher should "convince". The age characteristics of the development of middle-aged and older students imply a minimal authority of a teacher. Besides, not every student is ready to share personal experiences with a stranger - a teacher. Here, the contact between parents and the child becomes more relevant.

And again the facts of modern life. The distance learning period has shown that not all parents and their children are ready for dialogue. In addition, often parents' ability to work with information gadgets is several times lower than that of children. Therefore, parents do not know and cannot ensure the safety of their child when working in the global network and with DLT.

5. Introduce the rules of conduct on forums and chats, convince them that they should not use the network for hooliganism, spreading gossip, or threatening other people. The teacher is facing a very difficult task. It is difficult to convince a teenager of anything when in the society where they live, such facts are considered common practice.

6. Convince to never give out personal information, including last name, first name, home address, phone numbers, school name, email address, last names of friends or relatives, their names in instant messaging programs, age or date of birth, by email, in chat rooms, instant messaging systems, registration forms, personal profiles and when registering for competitions on the Internet.

One of the ways to present the professional and pedagogical achievements of teachers to society (including for the analysis of professional activities in terms of certification) is to post information on websites and their own pages on social networks. Moreover, now almost every relatively popular person already has his own page in social networks. In these conditions, the teacher is forced to publish a lot of different, as well as personal, information about themselves, their activities, and about their students. A contradiction arises: how can a teacher convince students not to give personal information to anyone if they post it on the global network themselves.

Recommendations such as:

- $\quad$ show interest in the "virtual" life of your students, and if necessary, inform parents about the problems of their children;

- teach students to be attentive to information received from the Internet. Insist on visiting trusted sites;

- $\quad$ in case of problems related to Internet addiction, promptly bring the information to the attention of parents, involve a psychologist, social teacher to work with students and their parents

We conducted an experiment: we interviewed a group of parents and their children, and then we compared the answers. As the study has shown, the overwhelming majority of parents 1) have a vague idea of the interests of their child on the Internet (what games they play, what websites they visit, which mailings they are subscribed to) - 64 out of 83 people (Figure 1);2) do not have a sufficient level of information technology, for example, to establish parental control on a home computer (79 out of 83 people), etc.

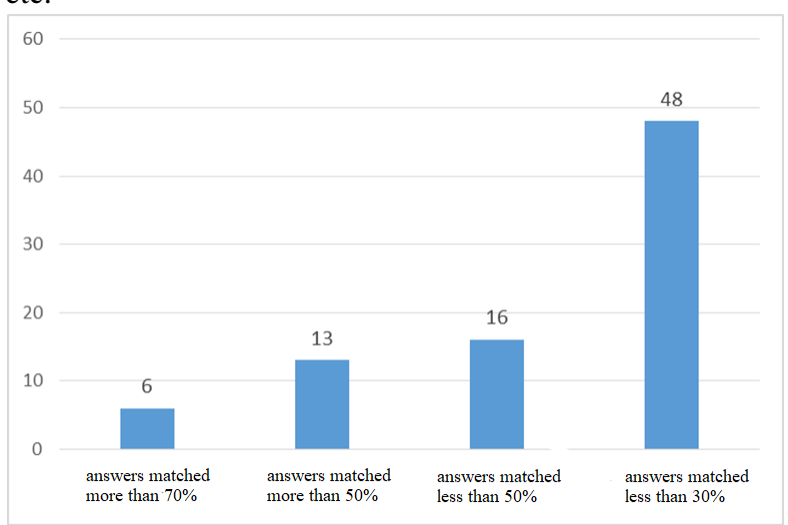

Figure 1: Awareness of parents about the interests of their child on the Internet

In this context, the results of a survey of children about the websites they visit should be noted (Figure 2).

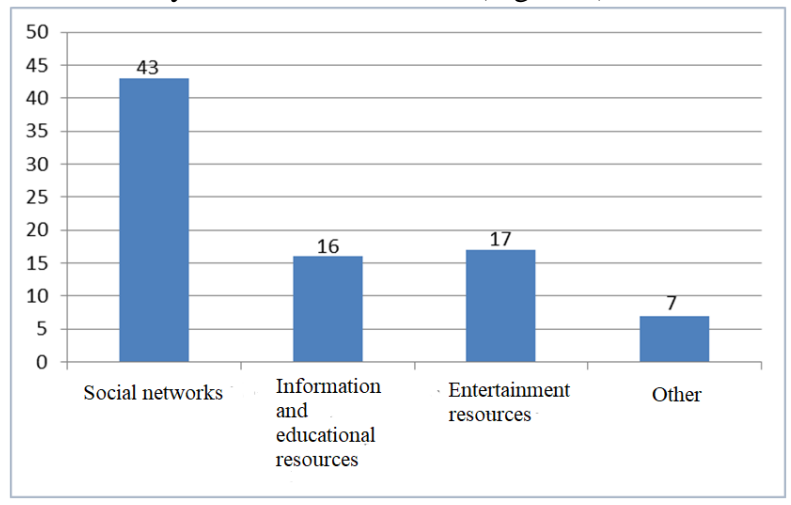


Figure 2: Internet resources visited by children

We've also found that children do not clearly understand what exactly relates to personal information. In this regard, there is a great probability of providing information of a confidential nature that children post on the Internet. This is also proved by the survey results presented in Figure 3 .

The results of the conducted research also indicate the need to pay special attention to the psychological side of the use of DLT and Internet technologies in the teacher's activity, on the one hand, and on the other, the importance of these technologies for children in the emotional and value-based sense $[2,5]$.

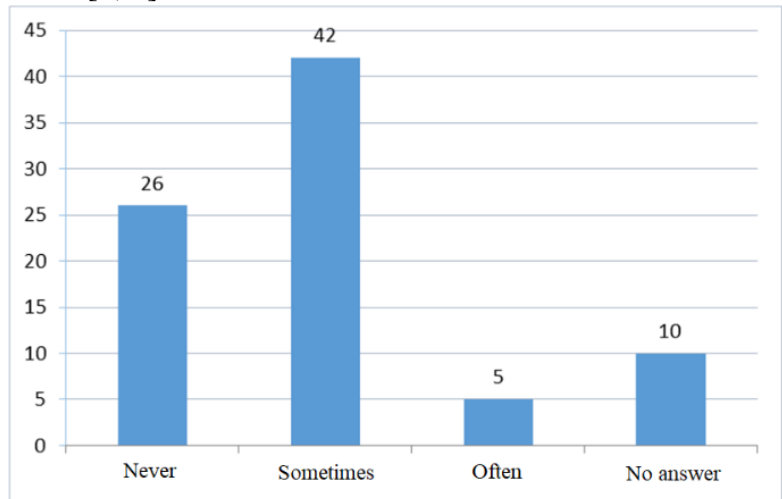

Figure 3: Providing confidential information on the Internet

The conducted research also showed an insufficient level of proficiency in IC competencies by teachers. During the survey, teachers noted the presence of such skills as using information technology to demonstrate various kinds of documents; creating presentations, text documents; performing and completing computer testing; using the Internet to collect information, participation in teleconferences, getting access to scientific, pedagogical and methodological data.

At the same time, teachers, students of advanced training courses, identified the need to develop skills in processing graphic files, audio, and video information, creating videos. In addition, a mandatory condition should be a significant prevalence of practical exercises using a computer over theoretical ones.

\section{DISCUSSION OF FINDINGS}

As a result of the analysis and generalization of the obtained empirical data, the following programs of advanced training courses were developed: "Improvement of the teacher's pedagogical technique using information technologies", "Visualization by means of information and communication technologies in the activities of an educational organization", "Multimedia technologies in the activities of an educational organization", "Didactic aspects of ICT, digital and network resources in the educational process", "General pedagogical ICT competence of a preschool educational institution teacher in the context of the introduction of the Federal State Educational Standard of preschool education". The programs have successfully passed the inspection and were included in the Republican Bank of Additional Professional Programs of the Udmurt Republic.

The courses include the following modules:

- Teacher's pedagogical technique in modern information education. The following are studied: the role of modern information technologies in the pedagogical technique of the teacher; problems of evaluating the effectiveness of pedagogical technique; the use of information technology in the pedagogical technique of the teacher; methods for assessing the effectiveness of the pedagogical technique.

- Processing of graphic information. Techniques for working with software for processing graphic information are being studied.

- Processing of video information. The following are studied: various types of software for processing video information; methods of working with software for processing video information.

- Sound information. The following are studied: types of software for processing sound information; methods of working with software for processing sound information

- Development of multimedia videos for educational purposes. The techniques of working with software for creating multimedia videos for educational purposes are being studied.

- Information culture. The following concepts are studied: information society, information culture, information competence, personal data, digital competence, digital generation, digital environment, digital socialization, the theory of generations by N. Howe and U. Strauss, verbal expressions used on the Internet (trolling, cyberbullying, grooming, flaming, etc.), Google effect, clip thinking, network thinking, multitasking phenomenon, etc.

- Information security. The issues of ensuring the information security of the child's identity, family, educational institution, modern concept, regulatory legal acts in the field of information security, Internet risks, Internet resources (www.fid.su, www.detionline.com, www.saferunet.ru, www.i-deti.org, https://safety.google/families/, etc.), Internet technologies and services, methods and means of identifying threats to identity and information, safe use of software and hardware tools in professional teaching activity.

- Psychological and pedagogical support of teenagers. The following are studied: patterns of knowledge formation on information security among teenagers, mechanisms of information perception, causes of information stress, acquaintance, and methods of working with empirical and diagnostic tools in the teaching activity.

- DLT. Tools for organizing distance learning are being studied. Digital Learning Management Systems (Moodle, Google Classroom, etc.). Programs that provide the ability to work online together (Skype, Zoom, etc.). 
- The content of the presented courses confirms once again how much work still needs to be done in order to increase the effectiveness of teachers' pedagogical techniques to ensure the physical, mental, spiritual, and moral health of students in the distance learning implementation.

\section{CONCLUSION}

The analysis results of the feedback received from the teachers who studied at the advanced training courses for the selected programs have confirmed the feasibility of using these programs and the increase of the IC and information security competencies of teachers in the context of the DOT implementation. The programs acquire particular practical significance when the coronavirus pandemic, on the one hand, breaks the traditional social communication between teachers, students and their parents, translating it into a digital channel, and on the other hand, gives a new impulse towards the development of online education using new distance learning tools.

\section{REFERENCES}

[1] S.T. Gubina, N.L. Yugova, Teenagers' Perception of Information on the Internet: Prevention of Internet Addictive Behavior, Discussion 1 (42) (2014) 111-117.

[2] V. A. Slastenin, I. F. Isaev, A. I. Mishchenko, E. N. Shiyanov, Pedagogy: a textbook for students of pedagogical educational institutions - Moscow: ShkolaPress, 2002.

[3] O.N. Utkina, S.T. Gubina, N.L. Yugova, The development of pedagogical technique of teachers in a distance study conditions, Proceedings of the $1 \mathrm{st}$ International Scientific Conference "Modern Management Trends and the Digital Economy: from Regional Development to Global Economic Growth" (MTDE 2019), vol. 81, 2019, pp 542-545. doi.org/10.2991/mtde-19.2019.108

[4] O. N. Utkina, Quality assurance of teacher's pedagogical techniques by means of information technologies, Indian Journal of Science and Technology 9 (14) (2016). http://www.indjst.org/index.php/indjst/article/view/910 98

[5] I. A. Baeva, Psychological safety of the educational environment of the school and its psychological and pedagogical support, Psychological Science and Education 3 (2012) 30-40.
[6] Yu.I. Bogatyrev, A.N. Privalov, Information security of the individual: topical issues of psychological and pedagogical support and support for schoolchildren. Humanities 1 (33) 2016.

[7] G.V. Grachev, Information and psychological security of the individual: state and possibilities of psychological protection. Moscow: RAGS Publishing House, 1998.

[8] N.I. Sattarova, Information security of schoolchildren in an educational institution: Diss. ... Cand. ped. sciences. - SPb., 2003.

[9] S.V. Molchanov, O. V. Almazova, N. N. Poskrebysheva, K. A. Kirsanov, Cognitive Processing of Social Information in Internet and Features of Moral Consciousness in Adolescents, Psychological Science and Education 23 (5) (2018) 77-86. doi: $10.17759 /$ pse.2018230508.

[10] V.I. Panov, E.V. Patrakov, Representations of Teachers and Elder Schoolchildren about the Risks of Interacting with the Internet, Psychological Science and Education 25 (3) (2020) 16-29. doi: 10.17759 / pse. 2020250302 .

[11] G.U. Soldatova, T.A. Nestik, E.I. Rasskazova, E.Yu. Zotova, Digital competence of adolescents and parents. The results of the all-Russian study - Moscow: Internet Development Fund, 2013.

[12] Methodological recommendations and information on activities, projects and programs aimed at increasing the information literacy of teachers.

http://bogur.bkobr.ru/attachments/ article / 1473 / metodicheskie_rekomendacii.pdf 